\title{
THE EFFECT OF CALCINATION TEMPERATURE ON THE
} CHEMICAL COMPOSITION OF OYSTER, PERIWINKLE AND SNAIL SHELL ASH

\author{
Anieti-mfon E. Inyang ${ }^{1}$, Benjamin R. Etuk ${ }^{2}$ \\ ${ }^{I}$ Department of Chemical and Petroleum Engineering, University of Uyo, Uyo 52001, Nigeria \\ ${ }^{2}$ Department of Chemical and Petroleum Engineering, University of Uyo, Uyo 52001, Nigeria
}

\begin{abstract}
Mollusk shells of oyster, periwinkle and snail were ashed at temperatures of $900^{\circ} \mathrm{C}, 1000^{\circ} \mathrm{C}, 1200^{\circ} \mathrm{C}, 1400^{\circ} \mathrm{C}, 1600^{\circ} \mathrm{C}$. The resulting ash which are known to be pozzolanic in nature were analyzed for the clinker compounds using the $x$-ray florescence method and the Bougue equations. The results show that the three mollusk shell ashes at all the ashing temperatures studied had high concentration of tricalcium silicate $\left(C_{3} S\right)$ of between $178.77-232.43 \%$ and low concentration of tricalcium aluminate $\left(C_{3} A\right)$ and tetracalcium aluminoferrite $\left(C_{4} A F\right)$ of up to $0.14 \%$ and $1.22 \%$ respectively. Dicalcium silicate $\left(C_{2} S\right)$ was not present in detectable concentration. The low concentrations of the clinker compounds may be attributed to the low quantity of $\mathrm{SiO}_{2}, \mathrm{Al}_{2} \mathrm{O}_{3}$, $\mathrm{SO}_{3}$ and $\mathrm{Fe}_{2} \mathrm{O}_{3}$ in all the ashes at the temperatures studied.
\end{abstract}

Keywords: Cement, Concrete, Admixtures, Mollusk Shells, Waste Utilization, Cement Replacement Materials

\section{INTRODUCTION}

Ordinary Portland cement is extensively used as material for construction purposes such as a binder, in production of mortar, in production of blocks etc. However, the cement manufacturing process is capital and energy intensive and there is serious environmental concerns regarding rapid depletion of limestone which is the raw material used for cement production and $\mathrm{CO}_{2}$ emission during cement manufacturing process. These have brought pressure to reduce cement consumption by the use of cement replacement materials (CRMs). Studies had been done where waste materials such as rice husk ash (Farah, Ramadhansyah, Badorul and Megat, 2011), groundnut shell ash (Mahmoud, Belel and Nwakaire, 2012), mollusk shell ash (Etuk, Etuk and Asuquo, 2012), bamboo leaf ash (Umoh and Ujene, 2014), sugar cane bagasse (Hussein et al, 2014), saw dust ash (Udoeyo and Dashibil, 2002), corn cub ash (Adesanya and Raheem, 2009) had been used as CRMs with encouraging results.

Each year, a lot of mollusks such as oyster, periwinkle and snail are consumed in large quantity in Nigeria and the total amount shall increase steadily as population increases. A large part of the shells generated are dumped into the environment where they deface the surrounding and constitute environmental nuisance.

Mollusks shells are known to be large reservoir of minerals, chief of which is calcium trioxocarbonate (IV) $\left(\mathrm{CaCO}_{3}\right)$ (zhong, Zhou, Chan and Yuyan, 2012). According to Yang, Yi and Leem (2005); Ballester, Mármol, Morales and Sánchez (2007) the chemical composition of shells is greater than $90 \%$ calcium carbonate $\left(\mathrm{CaCO}_{3}\right)$ by weight; this composition is similar to limestone powder or dust-like stone powder from grinding limestone to produce Portland cement. Interestingly, the crystal structures of oyster shells are largely composed of aragonite and calcite, which have higher strengths and densities than limestone powder (Mosher, Cope, Weber, Shea and Kwak, 2010).

For studies like those of Badmus, Audu and Anyata (2007) and Etuk, Etuk and Asuquo (2012) done on the utilization of ash produced from this mollusk shell as pozzolanic admixture, shell calcination was done at temperatures below $1000^{\circ} \mathrm{C}$. Analysis for important clinker compounds which are usually formed at very high temperature of between $1000^{\circ} \mathrm{C}$ and $1600^{\circ} \mathrm{C}$ were not carried out. This necessitated this study which is focused on subjecting mollusk shells to temperatures as high as $1600^{\circ} \mathrm{C}$ to encourage the formation of these important clinker compounds which may increase the effectiveness of the ashes formed as a cement replacement pozzolanic material.

\section{MATERIALS AND METHODS}

The materials used in carrying out this study were periwinkle, snail and oyster shells ash. Other materials used were UNICEM ${ }^{\circledR}$ ordinary Portland cement, water and sand. The shells were obtained from dump sites at Akpan Andem Market in Uyo, Akwa Ibom State, Nigeria.

\subsection{Production of Shell Ash}

The different shells sample were each washed thoroughly to remove all dirt and sundried for five (5) days. After sufficient drying had been achieved, the different shell samples were then calcined in a Gallenkamp Muffler Furnace with serial Number 1B2613B. Each shell sample was calcined at five different temperature of $900^{\circ} \mathrm{C}, 1000^{\circ} \mathrm{C}$ 
$1200^{\circ} \mathrm{C}, 1400^{\circ} \mathrm{C}$ and $1600^{\circ} \mathrm{C}$. The ash samples were allowed to cool in a desiccator and then ground into very fine powder using a ceramic mortar and pestle, sieved through a BS sieve of 75microns, and kept in air tight containers (Etuk et al, 2012).

\subsection{Chemical Analysis}

The composition of the various shell ash samples were determined by analysis laboratory using an X-ray Fluorescence (XRF) Machine (PANalytical) with serial number DY1036 in accordance with Nigerian Industrial Standard (NIS) method (NIS, 2009). In the method, stearic acid $(0.4 \mathrm{~g})$ and $20.0 \mathrm{~g}$ of each of the different shell ashes were measured and put in a grinding pot and ground for 60 seconds using the Herzog grinding machine. The aluminum cup was filled half way with stearic acid and then filled up with the samples. The cup was carefully inserted into the pellet making machine (Herzog pressing machine). The pellet produced was then placed in the cement X-ray spectrophotometer and the programme to which the samples were analysed was selected, that is, the program OPC, and the start key was clicked so that within 2-3 minutes the results were obtained (Abdulfattah, 2001). This procedure was repeated for UNICEM ${ }^{\circledR}$ Portland cement as control. The Bogue equations given in equations 1 to 4 were then used to determine the principal oxides tricalcium silicate $\left(\mathrm{C}_{3} \mathrm{~S}\right)$, dicalcium silicate $\left(\mathrm{C}_{2} \mathrm{~S}\right)$, tricalcium aluminate $\left(\mathrm{C}_{3} \mathrm{~A}\right)$, tetra calcium alumino ferrite $\left(\mathrm{C}_{4} \mathrm{AF}\right)$ (Gupta and Gupta, 2012)

$\mathrm{C}_{3} \mathrm{~S}=4.07(\mathrm{CaO})-7.60\left(\mathrm{SiO}_{2}\right)-6.72\left(\mathrm{Al}_{2} \mathrm{O}_{3}\right)-1.48\left(\mathrm{Fe}_{2} \mathrm{O}_{3}\right)-$ $2.85\left(\mathrm{SO}_{3}\right)$

$\mathrm{C}_{2} \mathrm{~S}=2.87\left(\mathrm{SiO}_{2}\right)-0.754\left(\mathrm{C}_{3} \mathrm{~S}\right)$

$\mathrm{C}_{3} \mathrm{~A}=2.65\left(\mathrm{Al}_{2} \mathrm{O}_{3}\right)-1.69\left(\mathrm{Fe}_{2} \mathrm{O}_{3}\right)$

$\mathrm{C}_{4} \mathrm{AF}=3.04\left(\mathrm{Fe}_{2} \mathrm{O}_{3}\right)$

\section{RESULTS AND DISCUSSION}

The chemical composition of the OPC used as control and the shell ashes are given in Table 1. The results show that the cement used, have the four major compounds, namely, $\mathrm{CaO}, \mathrm{SiO}_{2}, \mathrm{Al}_{2} \mathrm{O}_{3}$, and $\mathrm{Fe}_{2} \mathrm{O}_{3}$, with high percentage of $\mathrm{CaO}$.

Also the results for each of the shell ashes show that they contain the main chemical compounds of cement namely, $\mathrm{CaO}, \mathrm{SiO}_{2}, \mathrm{Al}_{2} \mathrm{O}_{3}, \mathrm{SO}_{3}$ and $\mathrm{Fe}_{2} \mathrm{O}_{3}$, depending on the calcination temperature and this similarity in chemical composition with that of OPC makes the partial replacement of cement by each of the shell ashes to be feasible. From the data presented, the amount of sulphur trioxide $\left(\mathrm{SO}_{3}\right)$ present in each of the shell ashes lies within the optimum recommended range of not more than 4.0\% (ASTM, 2015). However, the results show that PSA contains more $\mathrm{SO}_{3}$ followed by OSA and SSA.
The major clinker compounds in the OPC used as control and the shell ashes produced as calculated from equations 14 are shown in Table 4.2. The results show that OPC has $\mathrm{C}_{3} \mathrm{~S}, \mathrm{C}_{2} \mathrm{~S}, \mathrm{C}_{3} \mathrm{~A}$ and $\mathrm{C}_{4} \mathrm{AF}$ as $41.46 \%, 29.18 \%, 10.01 \%$ and $9.88 \%$ and is within the acceptable ASTM range for Portland cement type I (Lea, 2015).

The three mollusk shell ashes have high concentration of $\mathrm{C}_{3} \mathrm{~S}$ of between $178.77-232.43 \%$ at all temperatures studied which is greater than $41.23 \%$ obtained for OPC. This can be attributed to low quantity of $\mathrm{SiO}_{2}, \mathrm{Al}_{2} \mathrm{O}_{3}, \mathrm{SO}_{3}$ and $\mathrm{Fe}_{2} \mathrm{O}_{3}$ in all the shell ashes at all temperature.

The three mollusk shell ashes have low concentration of $\mathrm{C}_{3} \mathrm{~A}$ at all the temperature studied of up to $0.14 \%$. This can be attributed to the low quantity of $\mathrm{Al}_{2} \mathrm{O}_{3}$, and $\mathrm{Fe}_{2} \mathrm{O}_{3}$ in the shell ashes.

The three mollusk shell ashes also have low concentration of $\mathrm{C}_{4} \mathrm{AF}$ at all temperatures studied of up to $1.22 \%$. This can be attributed to the low quantity of $\mathrm{Fe}_{2} \mathrm{O}_{3}$ in the shell ashes.

It was however observed that dicalcium silicate $\left(\mathrm{C}_{2} \mathrm{~S}\right)$ and Magnesium oxide $(\mathrm{MgO})$ were not present in detectable concentrations in the ash produced.

With the presence of $\mathrm{C}_{3} \mathrm{~S}, \mathrm{C}_{3} \mathrm{~A}$ and $\mathrm{C}_{4} \mathrm{AF}$ in the shell ashes, it is certain that properties of concrete such as setting time and compressive strength with these ashes as admixture shall be affected.

\section{CONCLUSION}

The following conclusions were drawn from the study:

1. Each of the shell ashes contain the main chemical compounds of cement namely, $\mathrm{CaO}, \mathrm{SiO}_{2}, \mathrm{Al}_{2} \mathrm{O}_{3}, \mathrm{SO}_{3}$ and $\mathrm{Fe}_{2} \mathrm{O}_{3}$, depending on the calcination temperature.

2. The three mollusk shell ashes contain high concentration of $\mathrm{C}_{3} \mathrm{~S}$ between $178.77-232.43 \%$ at all temperatures studied, which is greater than $41.23 \%$ obtained for OPC.

3. $\mathrm{C}_{2} \mathrm{~S}$ was not detectable in the three mollusk shell ashes at all the temperature studied. This can be attributed to the low quantity of $\mathrm{SiO}_{2}$ in the shell ashes and the high quantity of $\mathrm{C}_{3} \mathrm{~S}$

4. The three mollusk shell ashes have low concentration of $\mathrm{C}_{3} \mathrm{~A}$ at all the temperature studied of between $(-0.46)-$ $0.14 \%$.

5. The three mollusk shell ash have low concentration of $\mathrm{C}_{4} \mathrm{AF}$ at all temperatures studied of between 0.00 and $1.22 \%$. 
Table 1 Oxide composition of OPC and mollusk shell ash

\begin{tabular}{|c|c|c|c|c|c|c|c|c|c|}
\hline \multirow[t]{2}{*}{ Shell type } & \multirow{2}{*}{$\begin{array}{l}\text { Calcinati } \\
\text { on Temp. } \\
\left({ }^{\circ} \mathrm{C}\right)\end{array}$} & \multicolumn{8}{|c|}{ Composition (\%) } \\
\hline & & $\mathrm{SiO}_{2}$ & $\mathrm{Al}_{2} \mathrm{O}_{3}$ & $\mathrm{Fe}_{2} \mathrm{O}_{3}$ & $\mathrm{CaO}$ & $\mathrm{MgO}$ & $\mathrm{SO}_{3}$ & $\mathrm{~K}_{2} \mathrm{O}$ & $\mathrm{Na}_{2} \mathrm{O}$ \\
\hline \multirow{5}{*}{ OSA } & 900 & 1.06 & 0.03 & 0.00 & 55.41 & 0.00 & 0.00 & 0.00 & 0.00 \\
\hline & 1000 & 0.87 & 0.02 & 0.00 & 55.44 & 0.00 & 0.11 & 0.00 & 0.00 \\
\hline & 1200 & 4.37 & 0.07 & 0.00 & 53.24 & 0.00 & 0.11 & 0.00 & 0.00 \\
\hline & 1400 & 0.00 & 0.03 & 0.14 & 55.20 & 0.00 & 0.13 & 0.00 & 0.00 \\
\hline & 1600 & 0.00 & 0.05 & 0.04 & 56.74 & 0.00 & 0.12 & 0.00 & 0.00 \\
\hline \multirow{5}{*}{ PSA } & 900 & 1.08 & 0.08 & 0.40 & 54.69 & 0.00 & 0.13 & 0.00 & 0.00 \\
\hline & 1000 & 2.32 & 0.04 & 0.08 & 54.73 & 0.00 & 0.15 & 0.00 & 0.00 \\
\hline & 1200 & 3.79 & 0.13 & 0.39 & 53.83 & 0.00 & 0.27 & 0.00 & 0.00 \\
\hline & 1400 & 5.17 & 0.15 & 0.15 & 54.21 & 0.00 & 0.47 & 0.01 & 0.00 \\
\hline & 1600 & 3.51 & 0.09 & 0.08 & 55.79 & 0.00 & 0.16 & 0.00 & 0.00 \\
\hline \multirow{5}{*}{ SSA } & 900 & 0.76 & 0.02 & 0.00 & 55.79 & 0.00 & 0.08 & 0.02 & 0.00 \\
\hline & 1000 & 0.00 & 0.02 & 0.00 & 55.90 & 0.00 & 0.80 & 0.02 & 0.00 \\
\hline & 1200 & 0.00 & 0.08 & 0.00 & 57.30 & 0.00 & 0.11 & 0.05 & 0.00 \\
\hline & 1400 & 0.08 & 0.07 & 0.06 & 57.23 & 0.03 & 0.11 & 0.04 & 0.00 \\
\hline & 1600 & 0.08 & 0.02 & 0.07 & 57.38 & 0.00 & 0.09 & 0.03 & 0.00 \\
\hline
\end{tabular}

Table 2 Major compounds present in OPC and mollusk shell ashes (Bouge's compound composition)

\begin{tabular}{|l|l|l|l|l|l|}
\hline Shell type & Calcination & \multicolumn{4}{l}{ Clinker compounds $(\%)$} \\
\cline { 3 - 6 } & Temp. $\left({ }^{\circ} \mathrm{C}\right)$ & $\mathrm{C}_{3} \mathrm{~S}$ & $\mathrm{C}_{2} \mathrm{~S}$ & $\mathrm{C}_{3} \mathrm{~A}$ & $\mathrm{C}_{4} \mathrm{AF}$ \\
\hline \multirow{5}{*}{ OSA } & 900 & 217.26 & -160.77 & 0.08 & 0.00 \\
\cline { 2 - 6 } & 1000 & 218.58 & -162.31 & 0.05 & 0.00 \\
\cline { 2 - 6 } & 1200 & 182.69 & -125.21 & 0.19 & 0.00 \\
\cline { 2 - 6 } & 1400 & 223.89 & -168.81 & -0.16 & 0.43 \\
\cline { 2 - 6 } & 1600 & 230.20 & -173.57 & 0.07 & 0.12 \\
\hline \multirow{5}{*}{ PSA } & 900 & 212.88 & -157.41 & -0.46 & 1.22 \\
\cline { 2 - 6 } & 1000 & 204.30 & -147.39 & -0.03 & 0.24 \\
\cline { 2 - 6 } & 1200 & 188.06 & -130.92 & -0.31 & 1.19 \\
\cline { 2 - 6 } & 1400 & 178.77 & -119.96 & 0.14 & 0.46 \\
\cline { 2 - 6 } & 1600 & 199.21 & -140.13 & 0.10 & 0.24 \\
\cline { 2 - 6 } & 900 & 220.93 & -164.40 & 0.05 & 0.00 \\
\cline { 2 - 6 } & 1000 & 225.10 & -169.72 & 0.05 & 0.00 \\
\cline { 2 - 6 } & 1200 & 232.36 & -175.20 & 0.21 & 0.00 \\
\cline { 2 - 6 } & 1400 & 231.45 & -174.28 & 0.08 & 0.18 \\
\cline { 2 - 6 } & 1600 & 232.43 & -175.03 & -0.07 & 0.21 \\
\hline OPC & 41.46 & 29.18 & 10.01 & 9.88 \\
\hline
\end{tabular}

\section{REFERENCES}

[1] Abdulfattah, M. (2001). Determination of Chemical Analysis Using Pellets. in: A laboratory Manual of Quality Control, Ashakacem Plc., Gombe State, 1-12.

[2] Adesanya, D. A. and Raheem, A. A. (2009). Development of Corn Cob Ash Blended Cement. Construction and Building Materials, 23, 348-352.

[3] ASTM International (2015). Standard Specification for Coal Fly Ash and Raw or Calcined Natural Pozzolan for Use in Concrete, ASTM C618-15, West Conshohocken, PA.

[4] Badmus, M. A., Audu, T. O. and Anyata, B. U. (2007). Removal of Lead Ion from Industrial Wastewaters by Activated Carbon prepared from Periwinkle Shell (TypanotonusFuscatus). Turkish Journal of Engineering and Environmental Science, $31,251-263$.
[5] Ballester, P., Mármol, I., Morales, J. and Sánchez, L. (2007). Use of Limestone Obtained from Waste of the Mussel Cannery Industry for the Production of Mortars. Cement and Concrete Research 37, 559-564.

[6] Etuk, B. R., Etuk, I. F. and Asuquo, L. O. (2012) Feasibility of Using Sea Shells Ash as Admixtures for Concrete. Journal of Environmental Science and Engineering, A1, 121-127

[7] Farah, A. W., Ramadhansyah, P. J., Badorul, H. A. and Megat, A. M. (2011). Effect of Rice Husk Ash to the Performance of Concrete Block. International Journal of Applied Science and Technology 1, 53-61

[8] Gupta, B. L. and Gupta, A. (2012) Concrete Technology. India: Standard Publisher's Distributors, 618-643.

[9] Hussein, A. A., Shafiq, N., Nuruddin, M. F. and Memon, F. A. (2014) Compressive Strength and Microstructure of Sugar Cane Bagasse Ash Concrete. 
Research Journal of Applied Sciences, Engineering and Technology 7, 2569-2577

[10] Lea, F. M (2015). Cement: cement making process. Encyclopadia Britannica. [Online] available: http://www.britannica.com/technology/cementbuilding-material (April 2, 2015)

[11] Mahmoud, H., Belel, Z.A. and Nwakaire, C. (2012) Groundnut Shell Ash as a Partial Replacement of Cement in Sandcrete Blocks Production. International Journal of Development and Sustainability 1, 10261032

[12] Mosher, S., Cope W., Weber F., Shea D. and Kwak T. (2010). Effects of lead on Nap, Kp- ATPase and hemolymph ion concentrations in the freshwater mussel. Environmental Toxicology, 268-278.

[13] Nigeria Industrial Standard NIS (2009). Standards for Cement, NIS 412, Standard Organization of Nigeria, Abuja, Nigeria, 9-15.

[14] Udoeyo, F. F. and Dashibil, P. U. (2002) Sawdust Ash as Concrete Material. Journal of Materials in Civil Engineering, 14, 173-176.

[15] Umoh, A. A. and Ujene, A.O. (2014) Empirical Study on Effect of Bamboo Leaf Ash in Concrete. Journal of Engineering and Technology, 5, 71-82

[16] Yang, E. I., Yi, S. T., Leem, Y. M. (2005). Effect of oyster shell substituted for fine aggregate on concrete characteristics: part I. Fundamental properties. Cement and Concrete Research, 35, 2175-2182.

[17] Zhong, B., Zhou, Q., Chan, C. and Yuyan (2012). Structure and Property Characterization of Oyster Shell Cementing Material. JiegouHuaxue Chinese Journal, 31, 85-92. 